\title{
Energy and momentum associated with solutions exhibiting directional type singularities
}

\section{Ragab M. Gad}

Received: 18 September 2007 / Accepted: 26 September 2007 / Published online: 13 November 2007

(C) Springer Science+Business Media, LLC 2007

\section{Erratum to: Gen Relativ Gravit (2006) 38(3):417-424 DOI 10.1007/s10714-006-0230-4}

In the original article, Table 1 was unfortunately changed for another. The correct version is shown here

Table 1 The energy and momentum densities, using (EPM), for the Curzon metric

\begin{tabular}{lll}
\hline Prescription & Energy density & Momentum density \\
\hline Einstein & $\theta_{0}^{0}=\frac{1}{16 \pi}\left[-\frac{4 m^{2} r^{2}}{R^{6}}+\frac{4 m^{2}}{R^{4}}+2 e^{2 v}\left(-\frac{m^{2}}{R^{4}}+\frac{2 m^{2} r^{2}}{R^{6}}\right)\right]$ & $\theta_{\alpha}^{0}=0$ \\
Papapetrou & $\Omega^{00}=\frac{1}{16 \pi}\left[-e^{2 v-4 \lambda}\left(\frac{4 m^{4} r^{2}}{R^{8}}+\frac{12 m^{2}}{R^{4}}-\frac{16 m^{3} r^{2}}{R^{7}}+\frac{4 m^{2}}{R^{6}}\right)\right.$ & \\
Møller & $\Im_{0}^{0}=0$ & $\Omega^{\alpha 0}=0$ \\
& & $\Im_{\alpha}^{0}=0$ \\
\hline
\end{tabular}

The abbreviated letters (ELLPBM), in the last paragraph of discussion, become (ELLPB).

The online version of the original article can be found under doi:10.1007/s10714-006-0230-4. 